\title{
Jordanian Experience in Accreditation and Quality Assurance in HEIs
}

\author{
Prof. Majed Abu Jaber, Prof. Mohammad Walid Al Batsh \\ The University of Jordan, Amman, Jordan
}

\begin{abstract}
Quality assurance and accreditation in higher education aims to maintain and raise the quality of education and guarantee the improvement of its standards. It enables the institution to get the necessary input, refine the processes, and raise the standards of its output, in order to meet the previously defined goals and the needs of the stakeholders. This paper discusses issues of accreditation and quality assurance (QA) in Jordan's higher education institutions (HEIs), focusing primarily on the need for professionalism in accreditation and quality assurance, the historical development of accreditation and quality assurance practices, the establishment of the Higher Education Accreditation Commission (HEAC), standards and procedures of quality assurance carried out by HEAC, principles underlying Jordan's system of accreditation and quality assurance, quality assurance and improvement plans, challenges facing the implementation of quality assurance in Jordanian HEIs. The paper concludes with some recommendations for improving quality assurance in Jordanian HEIs.
\end{abstract}

Keywords: accreditation, quality assurance, higher education standards

\section{Introduction}

Accreditation and quality assurance in higher education is considered as one of the pillars in the development of education. It is closely connected to the components of the educational process (students, teaching staff, programs, teaching methods, labs computers, etc.). It is important especially in this era as our world is witnessing doors opened to various channels of knowledge in the time of globalization that affects our lives. The changing structure and delivery of higher education encompasses different types of educational institutions whether they are conventional or open (distance and open learning). These new realities and the growing demand for increased accountability and transparency to government, consumers, and the general public require new solutions related to the performance of quality assurance (QA). Quality assurance aims at guaranteeing the improvement of standards in higher education institutions (HEIs). It enables HEIs to get the necessary input, refine the process, and raise the standards of output in order to meet the goals set and the needs of students, employers and financiers, higher education. Accreditation on the other hand, is considered the cornerstone to achieving quality assurance and it has become almost universal. Stakeholders have a range of expectations about quality outcomes in higher education. The accreditation process, while responding to institutional and programmatic interests can play a major role by changing accreditation standards and placing a strong emphasis on performance outcomes, especially student learning outcomes.

Prof. Majed Abu Jaber, professor, Ph.D., College of Educational Sciences, The University of Jordan. Prof. Mohammad Walid Al Batsh, professor, Ph.D., College of Educational Sciences, The University of Jordan. 
And since quality assurance and accreditation in the domain of higher education and scientific research are a priority for the Arab academic institutions in general and for Jordan in particular, it is indispensable for an academic institution to undergo an overall evaluation which should be based on a number of quality criteria to assess the institution's commitment to them. In order for this to be appropriately done, Jordan Higher Education Accreditation Commission (HEAC) was established in 2007, in order to raise the competency level of higher education institutions in Jordan. HEAC has set a series of criteria and requirements that all institutions (public and private) must comply with in order to obtain full or partial accreditation for their programs.

The purpose of this paper is to trace and examine the development of QA and accreditation system implemented by Jordan Higher Education Accreditation Commission (HEAC) and its important role in the era of globalization to ensure the quality of education in Jordanian HEIs. It also points out the difficulties, weaknesses, and strengths in the current quality assurance and accreditation procedures in Jordan.

\section{Background}

Jordan is considered to be, by the Arab world, a leading nation in establishing scientific institutions. This fact is reflected in the sharp increase of public and private HEIs over the last four decades. Despite the scarcity of resources, burdens of nationalism, and its own modest abilities, Jordan's dedication to the amelioration of HEIs began since 1961, when Al-Hussein College opened a class to rehabilitate teachers and prepare them for teaching in schools.

This progress has been serving the needs of ambitious young individuals aspiring to advance in the highly saturated job market, by gaining a competitive edge at home as well as abroad. Consequently, quality and excellence in such institutions are paramount. Accreditation is the focal point, as it lays the foundation for quality and excellence. The concern for quality assurance and accreditation in higher education in Jordan began with the establishment of the first university 50 years ago.

The concern to continue this progress is an ongoing process due to the increased number of HEIs. Up till this moment, there are 10 public universities, 30 private universities, and 53 community colleges. This augmentation was a response to an increase in student enrolment. The number of students in Jordanian universities has grown from 34,000 in 1990 to approximately 244,794 in 2009 (HEAC, 2009). The expansion of the higher education system is also reflected in the large number of undergraduate and graduate programs. There are currently 1,142 specializations for the undergraduate degrees, of which 791 are offered by public universities and 351 are offered by private universities. A recent and projected downturn in enrolments has led to an imbalance between supply and demand for the higher education sector, and has thus increased the need for a more effective means of assuring academic standards, as well as effective institutional management and governance.

Stakeholders in Jordan agree that the uncontrolled expansion of HEIs, especially those in the private sector, has affected the quality of education and compromised the system's credibility. In the early nineties, a national consensus was established to guarantee a minimum level of quality for the existing undergraduate and graduate programs. In order to ensure that this would occur, legislation was promulgated in 1998 which established the Accreditation Council (AC). This legislation focused on the accreditation of private universities. Yet this was a matter of concern given that public universities continued to exceed capacity levels.

Public and private pressure heightened the demand on universities and on public officials to achieve an international standard for Jordanian HEIs. This was done in hopes of having Jordan become a regional/global 
center for higher education. In June of 2007, the AC was dissolved, and the Higher Education Accreditation Commission (HEAC) was established soon after. And to ensure that HEAC is an independent entity both financially and administratively, a modified law was issued on August 2nd, 2009.

HEAC's Council consists of a president, a vice-president, two full-time, and three part-time members, all of whom are of high academic and administrative qualifications. In addition, HEAC has 47 full-time staff members to carry out its day-to-day responsibilities.

HEAC's vision is to bring the Jordanian HEIs up to international competitiveness. Its mission is to elevate the Jordanian HEIs' performance and reinforce their competitive capabilities to reach national, regional, and international levels. It also aims to guarantee the implementation of accreditation and quality criteria to ensure the achievement of their objectives. This is done by assuring its quality, motivating HEIs to interact with national and international universities and scientific research centers as well as international accreditation and quality control commissions, and developing higher education through incorporating internationally comparable standards.

HEAC helps to provide the public assurance that the quality and standards of higher education are being safeguarded and enhanced. This is done by conducting academic reviews of higher education processes. In addition, it encourages HEIs to build their own manpower to ensure and control their inputs, processes, and learning outcomes.

\section{Importance of the Study}

(1) To evaluate HEAC experience in implementing accreditation and quality assurance standards used on Jordanian HEIs. This will help HEAC make the necessary decisions and take the required actions and steps to reform, modify, and develop its procedures and standards.

(2) To expose HEAC's systematized body knowledge, a common language, a set of standards and guidelines about what constitutes reliable and recognized accreditation and quality assurance procedures, standards, increasingly, programs and materials dedicated to train and help people working on it.

(3) To diagnose the challenges points of accreditation and quality assurance system, procedures, and standards.

(4) To help other countries benefit from Jordan's experience in the area of accreditation and quality assurance in the HEIs.

\section{Statement of the Problem}

This study aims to trace, review, and examine the development of the professionalism of the quality assurance and accreditation system implemented by HEAC. It also aims to recommend a future quality assurance and accreditation system that meets the international standards for quality assurance. In specific, it attempts to answer the following questions:

(1) What quality assurance and accreditation practices are currently being used in Jordanian HEIs?

(2) What are the major challenges of the various quality assurance practices?

(3) What are the recommendations that should be taken into account in order to conduct the quality assurance practices and elevate it to professionalism in Jordanian HEIs?

\section{Methodology}

The qualitative research methodology is implemented to collect the data needed. In specific, case studies are examined in order to meet the purpose of this paper. This method is selected as an empirical method of 
inquiry to investigate the Jordanian quality assurance professionalism within its real-life context, and allows for multiple sources of evidence to be used.

\section{Data Sources and Collection}

Multiple sources of evidence are used in order to get the required data. Researchers have collected data from available documents relating to accreditation and quality assurance practices at HEAC, and from the Jordanian HEIs. Open interviews with the people responsible for accreditation and quality assurance in Jordanian institutions were conducted, as well as focus group interviews with the staff of HEAC who are implementing the accreditation and quality assurance standards.

In order to respond rapidly to the country's needs, HEAC has developed its own standards of quality assurance. It has laid down these procedures and strategies in a manner that allows them to be applied to Jordanian institutions. In 2009, HEAC issued a guiding manual for these standards and procedures, and distributed it to all Jordanian HEIs.

HEAC monitors its accreditation criteria and standards of HEIs by implementing the following processes:

(1) Institutional (general) accreditation: a series of auditing and evaluative steps focusing on the institution as a whole, including its infrastructure, human resources both the academic as well as the administrative levels. It relates to the achievement of the institutional mission and objectives. It focuses on faculty members and teaching staff, area of the land and buildings' functional space, classrooms, library, admission, and registration.

(2) Program (special) accreditation: a series of auditing and evaluative procedures focusing on a degree-granting program within an institution of higher education, which is discipline-related preparing professionals for special occupations. It relates to professional expectations and requirements for entry and practice in a field. It focuses on program objectives, teaching plan, faculty members and staff, textbooks, journals, dictionaries and encyclopedias, laboratories and workshops (if applicable), tools and instructional materials, general requirements/administration and students.

Accreditation criteria have been developed based on the principles of continuous quality improvement and focus on the educational process as a whole. The principles of this approach rest on an underlying philosophy of quality.

\section{Quality Assurance (QA)}

Quality assurance is considered to be the process in which the quality of performance of HEIs is recognized for their procedures. This leads to quality outcomes, and holds the academic and educational communities accountable to the community. HEAC Law (20) of 2007 authorizes the Commission to establish QA Criteria for Jordanian HEIs and to apply such Criteria upon an institutional request willingness to obtain the certificate.

Despite the fact that Jordanian HEAC shares regional and international accreditation commissions the qualifying Criteria for applying to the QA certificate, and basic policies and expected levels of the achieved quality of the institution, it aims by applying the QA procedures to the Jordanian HEIs to achieve the followings:

(1) Encouraging excellence in Jordanian Higher Education institutions by developing tests and evidences guides to evaluate educational effectiveness of these institutions. 
(2) Encouraging institutional improvements that take up the educational process through constant self-evaluation practiced by the institution itself.

(3) Assuring the educational community as well as the public and other local, regional, and international bodies that the institution of concern has specific and appropriate educational objectives, and that it has provided suitable conditions through which it is able to achieve its objectives and mission effectively; it also maintains a stable level of achievements pertaining to such objectives and mission; it has an organizational structures filled by efficient and qualified cadres; and that it provides financial, physical, and human support which makes people expect the continuity of its distinguished and effective performance.

(4) Encouraging the positive competitive spirit among Jordanian Higher Education institutions towards excellence in their inputs, procedures and outputs with what goes along with the requirements of the local, regional and international communities, as well as with contemporary quality spirit, globalization and knowledge based economy.

HEAC developed a guide that includes explanations of all procedures required for obtaining the QA certificate. It begins with the Quality Assurance institution's application following and meeting the preconditions, procedures, and steps of awarding the certificate. The responsibilities and obligations of HEIs throughout the QA process can be categorized into the following:

(1) The responsibility of the institutions to carry out a self-evaluation study.

(2) The expert panel committee.

(3) The decision of awarding the certificate of Quality Assurance by the Board of the Commission should comply with several points including (a) the form and content of the decision; (b) methods of correction and grading against Quality Assurance Criteria.

(4) When HEAC has adopted Quality Assurance Criteria, it insisted on the Criteria for evaluation to be comprehensive, and was applicable to all HEIs in a manner that goes along with the international Criteria. Inputs, procedures, and outputs are considered vital. Twelve Criteria were developed to include 31 sub-dimensions (elements) to cover all aspects of services, procedures, and activities related to inputs, procedures and outputs. Every item subsumed under each Criterion is specified and defined together with a list of indicators which show that quality is addressed. A six-level scale has been established to be used for the assessment of the element under scrutiny. In addition, rubrics have been developed for each Criterion, which include six descriptive levels in order to assess each indicator. This addresses the issue and problem of lack of harmony in the judgments made by members of the expert-panel. The guidance of the expert-panel is sought by HEAC and those of the Quality Assurance to judge the quality of these institutions and to contribute to achieving accuracy, transparency, standardization, and institutionalism in the procedures followed by the Commission. When the rubrics of quality Criteria items indicate the levels of performance included that have been taken into consideration to be clear and procedurally to represent scaled levels in accordance with the (Guttman Scale) by which it is possible to scale the institutions successively and to scale the one institution in accordance with the degree of quality attained for the item or Criterion of concern. This will provide standardized and referential diagnostic information about weaknesses and strengths of Higher Education Institutions when they are compared one with another, or when the developing procedures and plans are determined by the institutions to adopt in their programs, administrative and academic procedures and services. Clear procedures have been designed to address quality assurance and their items in a way that ensures 
institutionalization of these procedures and the transparency in implementation, outcomes, flexibility, and carefulness of these procedures as advised by all review stake-holders.

The rapid development in the number of HEIs, particularly in the private sector seemed to affect the quality of education and raised the need for establishing a national quality assurance system that is based on systematic management and assessment procedures that are adopted to monitor performance and to ensure or to improve the achievement of specified quality. Quality assurance of HEIs in Jordan has been based on HEAC's enabling laws. It is a process of recognizing educational institutions for performance, integrity, and quality that entitles them to the confidence of the educational community and the public.

HEAC quality assurance system focuses on three stages:

(1) First stage: self-study evaluation: require the institutions to examine their own goals, procedures, achievements, etc. It assesses every aspect of the institution, including faculty members, staff, students, administration, and the governing board. It allows institutions to systematically analyze their systems for variance (objectives <-> outcome), make decisions based on fact, consciously define their organization's internal and external stakeholders, and actively seek input from both. It is a learning system that leads to continuous improvement of quality.

HEAC expects that each Jordanian institution is responsible for ensuring integrity in all its procedures dealing with its constituencies, and relationships with other institutions in general, and HEAC in particular when providing it with information, data etc. It also expects full cooperation from the institution during all aspects of the evaluation process. HEAC looks at the self-evaluation study as the most significant part of the quality assurance process. In addition, it expects the institutions to assess students' achievements regarding the programs and services offered to fulfill its educational objectives.

The aim of the self-evaluation study required by HEAC in order to obtain the quality assurance certificate is to understand, evaluate, and improve not merely to defend what already exists. The self-evaluation study is viewed by HEAC as an ongoing process to:

- Examining and analyzing the institutions' resources and their effectiveness in fulfilling its mission;

- Demonstrate that students' achievements are commensurate with the certificates and degree awarded;

- Apprise the relation of all institution's activities to its purpose;

- Provide a sound basis of institutional planning and improvement.

(2) Second stage: peer-reviews: a review that is done by fellow experts from relevant academic fields. It involves investigating the information the institution in question has provided to HEAC. The number of reviewers depends on the characteristics of the concerned institutions and the scope of its programs and services.

(3) Third stage: the decision of the Commission: It may include: granting accreditation; postponement until corrective action is completed; accreditation not granted.

- A percentage score is given based on the findings;

- The score is used by HEAC to determine whether or not the institution is to receive financial or recognition rewards.

This is followed by commendations for accomplishments and recommendations for improvements from HEAC's Council. 
Since the status of the accreditation and quality assurance is reviewed periodically, institutions are encouraged to have continuous evaluations and implement improvements. The quality assurance process implemented by HEAC is intended to:

(1) Foster excellence in HEIs through the development of criteria and guidelines for assessing educational effectiveness.

(2) Encourage institutional improvements through continuous self-evaluation.

(3) Ensure the educational community, the general public, other agencies and organizations that the concerned institution has clear defined and appropriate educational objectives, has established conditions under which their achievement can reasonably be expected, appears in fact to be substantially accomplishing them, well organized, have competent staff, and are expected to continue to do so.

(4) Provide advices and assistance to establish and develop institutions.

From the point view of HEAC, the effectiveness of the self-regulatory of quality assurance depends on Jordanian institution's acceptance of certain responsibilities, including involvement in and commitment to the quality assurance process. Jordanian institutions are expected to conduct an analytical self-evaluation study at the interval specified by HEAC (from one to two years), and at the end of the self-evaluation study, accept peer assessment concerning the institutions' strengths and weaknesses in regard to HEACs criteria and standards.

In doing the self-evaluation study, the institution should pay attention to the twelve criteria set by HEAC. They are as follows:

\section{The First Criterion: Vision, Mission and Objectives and Planning}

(1) Mission and objectives: The institution's vision and objectives are considered a determiner of its identity, including its educational activities, numbers of students, and its role in the framework of the Higher Education Institutions. Any evaluative process usually arises from the institution's definition of its mission, vision and objectives, and shows how far this mission had been realized.

(2) Planning and effectiveness: There must be an ongoing planning process to ensure that the institution achieves its vision, mission, and objectives. Continuous evaluation is required that the evaluation findings are used as a platform for planning and evaluation procedures and for the subsequent evaluation and in order to identify the questions that must be answered through the analysis of data and information obtained to modify its policy, objectives, and procedures and allocate resources accordingly.

\section{The Second Criterion: Educational Programs and Effectiveness}

(1) General Requirements: Offering university programs leading to graduate students competent in one of the disciplines of knowledge available. Maintaining high-quality in these programs is primarily the responsibility of the institution and HEAC in the second place. Hence, the evaluation of educational programs and the continuity of improvement and development is the continuing responsibility of the institution and the accreditation commission.

(2) Planning and Evaluation the Educational Programs: Planning for educational programs is based on the continuous and systematic evaluation in the light of the special needs of the specialization and field work program.

(3) Bachelor Programs (first degree): Programs are available to provide students with the knowledge and skills and basic skills, as well as the broad areas of knowledge. It is expected that the academic plans in any program offered include the followings: 
- University requirements (general education);

- Compulsory requirements (specialization);

- Elective.

The plans include basic academic specialization, related to oral and written communication, cognitive, quantitative analysis, critical and logical thinking, technological knowledge, skills related to research, and production of knowledge.

(4) Postgraduate Programs: The graduate programs are a set of advanced experience that follows the first university degree (Bachelor) and lead to a student to obtain master and/or doctorate degrees, which can be classified into two categories:

The first is to prepare students for the purposes of scientific research and to prepare qualified faculty members and researchers and able to provide students with the skills necessary for scientific research and knowledge discovery, production, institution, and dissemination.

The second is to prepare students professionally as it has evolved to the interpretation of the specific skills and organize information, as well as the development of analytical skills and performance necessary for professional practice and delivery.

(5) Faculty Members and Resources related to Graduate Programs: It is expected from the institutions that provide graduate programs to have faculty members that excel in their academic performance, and scientific research, who have a clear contribution to the advancement and development of knowledge. Success in such programs requires a commitment to provide various sources, whether they be human (faculty) or the physical or spatial or equipment and instruments or laboratories, libraries and learning materials, paper and electronic.

\section{The Third Criterion: Students and Student Services}

(1) Goals and organization of student services: The development of programs of students and student services support achieving the institutions' mission and objectives, by contributing in the development of knowledge and educational services to students. It is expected of each institution to provide basic services supportive of students, regardless of the level of programs provided.

(2) Responsibilities for programs of Student Development and Student Services: Institutions must provide programs and student services on the basis of assessing the needs of students and the institution's ability to provide adequate and appropriate support for them so as to ensure achievement of its objectives. And work to adopt policies for these programs and services, and work on updating and constantly checking and monitoring the effect of their implementation, and conduct periodic, systematic, and continuous evaluation.

(3) Academic evaluation of students and academic transcripts: The evaluation of academic performance of students should be based on clear and specific tests, and that the academic records of students should be accurate and comprehensive. The institution should establish procedures to maintain the integrity of these records from tampering, changing, and fraud.

(4) Student Services: Institutions must accept qualified students to cope with their environment and to provide them with appropriate instruction and support to achieve their educational goals.

\section{The Fourth Criterion: Faculty Members}

(1) Selection of faculty members and their evaluation, and professional growth: The process of selecting qualified faculty members and their development and retention are very important issues. The institution must have adequate and qualified faculty members to achieve its mission and objectives. 


\section{The Fifth Criterion: Scholarship, Scientific Research, and Innovation}

These are essential to the work of faculty members and students. It should be integrated with educational activities regardless of the size or nature of the institution. Scholarships are the main source for the sustainability of the faculty members in the institution.

The scientific research activities are directed towards building the scientific and/or modify the theories and the development of applied knowledge, which is an essential component of higher education as it serves two basic functions, the first: deepening and developing knowledge. And the second: training students on methodological approaches to acquire knowledge and prepare them for professional roles in their future as scholars, researchers, and practitioners. Innovations and creativity include the visual arts, literary, and performing arts that reflect the original ideas and interpretations and fantasies, ideas, and feelings.

\section{The Sixth Criterion: Library and Information Resources}

(1) The Library: The main objective of the library and information resources is to support the learning process, education, teaching, and research institution in a manner consistent with its mission and objectives. Providing an appropriate and adequate learning resources and quality services in line with the level of programs offered in the institution is of great importance in supporting the growth of mental, cognitive, and vocational students enrolled in the materials and programs regardless of their fields and the way it delivers.

(2) Resources of Information and Services: Resources of information and services must be effective in terms of quality, depth, diversity, and modernity to be able to support the programs offered by the institution.

(3) Facilities and Accessibility: Institution must provide appropriate facilities and adequate library and other related recourses of information such as tools, or qualified personnel and provide services to benefit students, faculty members, staff, and users outside of their institution, and through the Internet.

(4) Administration and Human Recourses: The institution should provide adequate human and qualified staff for the library and information resources in terms of number and various areas of specialization and must possess the necessary skills to provide services facilitating the process of using the library.

(5) Planning and Evaluation: The proper planning of the library and information resources to support teaching and learning functions should be provided in order to facilitate research by students and faculty members. The continuous evaluation of formal quality libraries and their collections and the possibility of using other resources of information and services aim to stand on their quality, effectiveness and contribute to support academic programs.

\section{The Seventh Criterion: Governance and Administration}

(1) A System of Governance and Administration: The governance and administration system contributes to achieving the institution's mission and objectives. The people concerned are those who deliver good governance by university departments and staff with institutional goals, priorities and plans, institutional and educational programs, thereby supporting the teaching and learning environment. Their commitment to quality and the development of effective measures ensure quality and work to improve the different areas through the maximum use of all the possibilities available there.

(2) The Council of Governance (Deans): The Council of Governance (Deans) will be responsible for the quality and integrity of the institution and the achievement of its mission, objectives, and governance of financial and policy-making and implementation. It is also responsible for follow-up of academic and administrative affairs in the administrative units and the various faculties of the institution. 
(3) Leadership and Administration: The President of the institution is responsible for determining and defining their objectives, priorities, and to develop appropriate plans which provide support for the learning environment and learning and ultimately achieve their goals and mission.

\section{The Eight Criterions: Financial Resources}

(1) Financial Planning: It is supposed that the financial planning and budgeting of ongoing activities be realistic and based on the institution's mission and objectives.

(2) Adequacy of Financial Resources: The financial resources must be judged on the adequacy of the institutions objectives and mission, and diversity in programs and services provided and number of students.

(3) Financial Administration: The administration and the financial administration system records and reports are the indicators of the financial integrity of the institution as it is the basis for decisions with financial professionals.

(4) Financial Investment and Development: The existence of a structured program reflects the institution's mission, objectives, and works to provide financial support from external resources are equivalent or equal in importance to planning the educational academic programs.

\section{The Ninth Criterion: Physical Resources}

(1) Teaching and Support Facilities: Designing effective material resources, especially those related to teaching and maintaining the facilities and administration (both within and outside the campus) contribute to the process of achieving the institution's mission and objectives.

(2) Equipment and Materials: Compatible and appropriate devices should be available in terms of varieties and number to facilitate the achievement of educational goals and objectives of the institution.

(3) Planning of Natural Resources: There must be a comprehensive planning of natural resources and be based on the Institution's mission and objectives.

\section{The Tenth Criterion: Institutional Integrity}

The institution should provide a high degree of integrity and commitment to ethical professional practices and credibility when presenting various reports either to the internal councils or the public opinion regarding the pedagogical status, scholarships, services, students, faculty members, employees, and the institution's relationship with various bodies in particular the Higher Education Council and the Commission for the Accreditation of Higher Education Institutions.

\section{The Eleventh Criterion: Interaction With the Community}

The institution should establish clear policies to interact with the local community. These policies should be based on sound realistic planning that coincides with the objectives of the institution. This relationship should be clear and based on mutual interest and benefit through establishing definite strategy and programs to set priorities. The institution with all its councils, faculty members, and personnel should show commitment to a complete cooperation with these bodies.

\section{The Twelfth Criterion: Administration of Quality Assurance}

The process of quality control and its administration is the process that identifies the degree of which the Institution carries out its duties and responsibilities according to quality criteria and regulations issued by HEAC in order to maintain the mission of this institution, its name, purpose, academic activities, and the 
quality of education provided to students. These matters require a special office in the institution to provide proof and evidence which confirm that the institution does its role and achieve its objectives effectively.

In order to implement the above QA criteria, a rubric is applied. In building the rubrics three criteria were considered: (1) design; (2) implementation; and (3) effectiveness.

In responding to HEAC's requirements, institutions need to set some policies, regulations, and processes to assure and enhance the quality of their educational programs. And to develop a fully integrated quality assurance system based on a set of the institution prescribed vision, mission, objectives, and principles for a quality assurance framework aimed at enhancing and assuring the quality of educational programs. This system should focus on:

- Studying the status quo of the university environment including faculties, departments, programs, students, etc. The management structure of the faculty must be identified (heads, deans, associate deans, academic and research and development, etc.) and their roles and responsibilities must be set. In addition, each program must be managed by a Program Team (PT) under the leadership of a Program Leader (PL). The PT consists of the staff responsible for the day-to-day management and facilitation;

- Describing the tasks, roles, and responsibilities of teams and individuals;

- Identifying the opportunities and challenges that the changes presented from a faculty perspective;

- Describing the strategies used to achieve the goals and conclude with an analysis of the successful factors;

- Commitment from the faculty and all employees to ensuring success.

A Program Quality Assurance (PQA) must be designed to ensure the quality system for all educational programs offered by the institution nationally and internationally. It should be framed by a set of guiding principles which include a list of criteria against which program quality is determined and a process for program accreditation. These guiding principles should include a holistic review of programs as well as a thoughtful and critical approach to the review itself, taking into account the changes in the environment that have impact on them. In addition, a commitment to meeting the requirements of HEAC, is in alignment between initial accreditation, ongoing program improvement and reaccreditation, regular reporting against specified criteria and external validation. Such criteria should be developed by various groups working closely with consultants and experts on quality assurance. These should include:

- The need for the program;

- Educational design including graduate capabilities and alignment between objectives;

- Equity including access to programs and support;

- Management including processes and documentation;

- Resources including staff capabilities and specialized facilities;

- Evaluation and maintenance including ongoing review of programs;

- Stakeholder requirements including the needs of professional accrediting bodies to support the quality assurance aspects.

\section{Challenges Facing Conducting QA in Jordan}

There are many challenges facing higher education in Jordan, which can be classified as follows:

\section{Increasing Demand for Higher Education}

There is an increase in the demand for higher education significantly in the past five years. This led burden 
on institutions of higher education, particularly at public universities, and led on the other hand, to invite the government to allow establishing private universities.

\section{The Absence of Orientation Towards Vocational Education}

The labor market in Jordan suffered from the growth in the number of university graduates and a shortage of skilled technicians and professionals. This problem has aspects of social, economic, and educational for many.

\section{Incompatibility Between the Outputs of Higher Education and the Requirements of the Market}

There is no harmony between national needs and licensing requirements of academic programs. In addition, it can be noted that there is absence in linkages between academic programs and curricula skills outputs the educational process. And the absence of a systematic institutional coordination between the outputs of higher education and the requirements of local and regional markets are changing. This can be seen by the dissatisfaction with local employers about the capabilities of graduates in terms of skills necessary for success in the labor market, the lack of current approaches to educational decisions that help to develop intellectual skills such as analytical thinking, communication, leadership, and institutional initiatives. And the lack of university support services to the satisfaction of students, such as exercise programs and training that meets the needs of the labor market skills or specific occupations, in addition to non-curricular activities. Also there is a repetition of the programs and areas of study and overlapping and duplication of disciplines under different names but the contents are similar, the inability of universities to influence the strategic standard methods at the national level with regard to flexible disciplines that meet the requirements of the changing labor market. In addition, there are inconsistencies with the needs of the local, regional and global labor markets as well as with the future trends of the new specialization required to meet the needs of the employers.

\section{Financial Challenges}

Public universities depend heavily on government subsidies and to the government budget support, which decreases with time (in 2005 form (20\%) of the total income of universities). The low government support and low tuition fees (which constitute (56\%) of the total income of universities) have led to:

- Low budgets for the infrastructure of the universities investment;

- Reduced funding for the development of the higher education sector, the financing of universities in traditional form and the absence of continuity after;

- Lack of/low financing activities aimed at developing a comprehensive strategic plan for higher education outputs, which forced universities to rely on its own resources and limited automatic and thus reduce the output.

\section{Drop in the Quality of the Educational Process}

Although the private higher education is subject to specific licensing procedures imposed by the Ministry of Higher Education before being allowed to put any disciplines and required to obtain accreditation of public and private before teaching; however, these measures only quantity, not quality. These measures aim to ensure a minimum level of quality with regard to curriculum, personnel, and laboratory facilities and resources of learning and teaching. The following are the major challenges facing the quality of higher education in Jordan.

\section{Admission Policies}

The challenges facing the admission policies, including the followings: 
- Lack of alignment between the performance of students in high school and selecting specialties, where their results in examination are the only factor taken into consideration for admission to university academic programs;

- Ignore the quality factor in the admission policies, especially in private universities in the acceptance parallel with programs at public universities;

- Absence of justice and consistency in the criteria for acceptance due to allocating special admission policies for some social groups.

\section{Faculty Members}

The challenges related to faculty members in HEIs as followings:

- Imbalance in the ratio of the number of students to the faculty member, in 2009, 1:29 in the public universities and 1:24 in private universities, while the international rates were 1:9 in Canada, 1:14 in the United States of America;

- The difficulty of recruiting qualified faculty in some programs;

- The absence of a clear policy for capacity building, such as training faculty members and support new members and the absence of transparent and fair appraisal system;

- The phenomenon of (brain drain), where it is attracting working in neighboring countries for higher salaries and incentives;

- Low investment, especially in scientific research in the universities, and lack of orientation towards expenditure on scientific research and motivation to conduct research and participation in international scientific conferences.

\section{Scientific Research}

The challenges facing the scientific research in Jordan are as follows:

- Low budgets for scientific research. In 2005, the budget allocated for scientific research in all Jordanian universities $(0.95 \%)$ only;

- Limited scientific research activities conducted by faculty members due to burden and lack of teaching facilities;

- Poor environment and skills trends to scientific research;

- Lack of cooperation between industry and HEIs.

\section{Management}

The challenges in management are as follows:

- Lack of harmony between the university management pattern and the requirements of the modern HEIs development;

- Lack of strategic planning in most HEIs;

- Low scholarships budget;

- Practices of "achievements in the last moment", and "accomplishments associated with pressures" in the institutions;

- Increased competition due to foreign universities entries and non-traditional education systems at the local and regional levels;

- Lack of promotional activities and marketing of HEIs in Jordan and abroad;

- The complexity of bureaucratic procedures faced by foreign students; 
- Lack of direction and guidance to students about educating programs in universities and colleges.

\section{Recognize the Importance of Quality Assurance}

This can be reflected as follows:

- Lack of vision, mission, and clear objectives to guide the work of Jordanian HEIs, which can be translated into strategic plans and academic curricula, learning to produce results desired for each specialty and each area;

- Low or non-allocation of budgets to invest in quality assurance;

- The absence of an integrated system for quality assurance in universities and colleges;

- Lack of assessment planning, and therefore the absence of a classification system for universities and academic programs in it;

- Some private HEI assume the profitability benchmark as a basis to maximize profit and this contradicts the standards of quality.

\section{Strategies and Actions}

To achieve a successful development and change of the PQA, a series of steps must be taken by the institution:

- Step 1. Establishing a sense of awareness and urgency;

- Step 2. Forming a powerful guiding coalition;

- Step 3. Creating a vision, and a mission;

- Step 4. Communicating the vision;

- Step 5. Empowering others to act on the vision;

- Step 6. Planning for and creating short-term wins;

- Step 7. Consolidating improvements and producing change;

- Step 8. Institutionalizing new approaches.

The strategy and outcomes must be communicated internally, to all levels within the Faculty and externally, and to relevant central committees and units within the institution.

\section{Results}

The findings for question one, "what quality assurance and accreditation practices are currently being used in Jordan HEIs?" are included in the background of the study.

Findings for question two, "what are the major challenges facing quality assurance practices?", after the researchers have completed a review of the documents of accreditation and quality assurance practices at HEAC, and the open interviews with the key persons in charge of accreditation and quality assurance in Jordanian universities, and the focus group interviews with the staff of HEAC who are implementing the accreditation and quality assurance standards, they came to the following strengths and weaknesses of the accreditation and quality assurance practices:

(1) The strengths of the Jordanian quality assurance and accreditation system and practices are summarized as follows:

- The establishment of a self-evaluation culture: The accreditation and quality assurance processes have contributed to the build-up of a self-evaluation culture at the HEIs. A number of Jordanian institutions have developed their own internal quality assurance systems as a result of HEAC's regulations, standards, and procedures; 
- The methodological model of quality assurance and accreditation applied by HEAC is in principle appropriate to control the quality of the Jordanian HEIs, and this model is in compliance with the world standards and practices of accreditation and quality assurance;

- The Jordanian model comprises most items and characteristics of European, American, and Australian models. It includes self-evaluation, external review by external experts etc.;

- It is a comprehensive model that deals with all HEIs such as public and private universities, and community colleges.

(2) The major difficulties and weaknesses of Jordan accreditation and quality assurance system include the followings:

- The limited staff capacity at HEAC, consequently, the technical and support staff are still not adequate;

- Lack of quality assurance culture within the institution leading to a small back-up of initiatives on this area;

- The reliance on national experts: There is a difficulty of finding a sufficient number of experts who are qualified and available to serve as peer reviewers. The use of experts peer reviewers creates a positive learning effect and contributes to creating a culture of quality;

- Lack of human resources to carry out the process of improvement (weak human capacity): The lack of appropriate trained personnel in institutions of higher education who are involved in the accreditation and quality assurance processes especially in collecting data, information, and self-analysis needed for effective self-studies. People do not know where to start, because they considered that this can be solved by a training course;

- Lack of material resources (limited funding): The lack of resources is perceived as posing a serious threat to the successful outcome of the self-assessment in Jordan universities;

- Lack of commitment from the institution administrators as well as faculty members;

- Difficulty in implementing improvement actions, and lack of staff commitment;

- People in charge of quality assurance offices in institutions are not competent in quality assurance issues. Or they do not have the power or the authority to make decisions.

In answering the third question, "what are the recommendations that should be taken into account in order to develop the quality assurance practices in Jordan HEIs?" Institutions should:

Identify improvement actions and implement such actions, in order to improve the quality of the service.

- Gain increased knowledge of the quality philosophy, and spread the quality assurance culture among all staff and employees;

- Encourage staff involvement in service improvement and staff awareness of the importance of quality assurance;

- Enhance employees', general public, and stakeholders' awareness of the importance of quality.

\section{Conclusion}

The philosophy of total quality management in higher education has been diversified to different schools. Subsequently, the Accreditation Council of Higher Education Institutions of Jordan (HEAC) took a very daring decision of not adopting any particular school of thought but rather to review all available models of total quality management and synthesize its own. 
The study pinpointed the major difficulties and weaknesses that HEAC faces. This concludes that HEAC in its endeavor should spread QA awareness to all HEI and stakeholders in the kingdom to ensure its quality, and set a future quality assurance and accreditation system that meets the international standards for quality assurance. In addition, it encourages HEIs to build their own manpower to ensure and control their inputs, processes, and learning outcomes.

Even though the model set by HEAC is a comprehensive model that deals with all HEIs such as public and private universities, and community, and is in compliance with the world standards and practices of accreditation and quality assurance such as NCATE (The National Council for Accreditation of Teacher Education), HEAC must still make the necessary decisions and take the required actions and steps to reform, modify, and develop its own procedures and standards.

Finally, the study concludes that institutions need to respond to HEAC's requirements, by setting some policies, regulations, and processes to assure and enhance the quality of their educational programs. And to develop a fully integrated quality assurance system based on a set of the institution prescribed vision, mission, objectives, and principles for a quality assurance framework aimed at enhancing and assuring the quality of educational programs.

\section{References}

Daly, W. T. (1994). Teaching and scholarship: Adapting American higher education to hard times. Journal of Higher Education, $65,45-57$

Elton, L. (1992). Quality enhancement and academic professionalism. The New Academic, 1, 3-5.

Fiona, W., \& Alex, R. (2002). Using quality assurance to drive a teaching and learning agenda: Taking a risk, meeting the challenge. In A. Goody, J. Herrington, and M. Northcote (Eds.), Quality conversations: 2002 Annual International Conference of the Higher Education Research and Development Society of Australasia (pp. 687-694), Perth, Western Australia.

Higher Education Accreditation Commission (HEAC). (2009). A guide to accreditation and quality assurance criteria in institutions of higher education. Amman, Jordan: Jordan University Press.

Hope, A. (2001). Building capacity for quality. Paper presented at Conference on Quality, Standards and Recognition, INQAAHE.

Manila, B. (2009). Quality assurance in Philippine higher education; lessons learned. Retrieved August 23, 2009 from HighBeam Research http://www.highbeam.com/doc/1G1-76827606.html

Obnami, M. (2001). New development of quality assurance of Japanese universities: The growing importance of the role of JUAA. Paper presented at Conference on Quality, Standards and Recognition, INQAAHE.

Schray, V. (2005). Assuring quality in higher education: Recommendations for improving accreditation (Fourteenth in a series of issue papers released at the request of Chairman Charles Miller to inform the work of the commission). USA: The Secretary of Education's Commission on the Future of Higher Education.

Yang, R. (2009). Global perspectives on quality in higher education [Review of the book Globalization and education: The quest for quality education in Hong Kong]. Australian Journal of Education. Retrieved August 30, 2009 from HighBeam Research http://www.highbeam.com/doc/1G1-110731330.html 